\title{
Has the Demand for Fats and Meats in the United States been Affected by the Health Claim on Risk of Coronary Heart Disease Issued by the Food and Drug Administration?
}

\author{
By Stavroula Malla* K. K. Klein ${ }^{ \pm} \&$ Taryn Presseau
}

\begin{abstract}
Health authorities are well aware that a healthy diet can be effective in reducing the risk of many chronic illnesses. To encourage greater consumption of healthy foods, some government agencies have begun issuing specific health claims on particular foods and/or ingredients. This study examines the impacts of a specific health claim on the risk of coronary heart disease on the demand for fats and meats in the United States. Results indicate the health claim decreased demand for foods higher in saturated fats and increased demand for foods lower in saturated fats by relatively small but statistically significant amounts.
\end{abstract}

Keywords: health benefits, functional foods, dietary choices, consumer demand

\section{Introduction}

In the United States, chronic illnesses are estimated to account for $75 \%$ of the $\$ 2$ trillion spent on annual healthcare costs and are one of the top causes of death and disability (Raghupathi and Raghupathi 2018). In addition to the direct costs of chronic illness, there are significant indirect costs including reduced labor market productivity, decreased quality of life and loss of opportunity (Public Health Agency of Canada 2014). Research has found that many chronic diseases, such as cardiovascular diseases (CVDs), obesity and diabetes, can be prevented or the risk can be significantly reduced through the adoption of a healthy lifestyle (Dietz et al. 2016). Leading health organizations such as the American Heart Association, World Health Organization (WHO), and Centers for Disease Control and Prevention (CDC) now strongly encourage consuming a healthy diet to help prevent and mitigate the risk of diet-related chronic illness (WHO 2003, American Heart Association 2017a, CDC 2017).

Growing consumer interest in health foods has been driven by greater understanding about the effects of diet on health as well as the motivation to improve well-being and longevity (Milner 1999, Moors 2012, Malla et al. 2013, Hobbs et al. 2014a). Policymakers also have placed greater emphasis on promoting the adoption of healthy diets as a preventative care strategy in an effort to help alleviate the rising economic burdens of chronic illness (Veeman 2002, Aschemann-Witzel 2011).

\footnotetext{
*Associate Professor, Department of Economics, University of Lethbridge, Alberta, Canada. ${ }^{ \pm}$Professor, Department of Economics, University of Lethbridge, Canada.

*Professional Affiliate, Department of Economics, University of Lethbridge, Canada.
} 
In the United States, the Food and Drug Administration (FDA) recognizes that certain foods, known as 'functional foods', provide extra health benefits and regulates the types of health claims that can be made on these foods. Health claims are statements that indicate a relationship between the consumption of a food and a health benefit (CFIA 2016). The main goal of these health claims is to help consumers make better dietary choices, improve population health, and reduce the direct and indirect economic burdens associated with diet-related illnesses that are placed on society each year.

Several "ex-ante" studies have found that health claims can improve consumer acceptance (e.g., Verbeke 2005, Teratanavat and Hooker 2006, Herath et al. 2008, Markosyan et al. 2009) as well as product evaluations and purchase intentions (e.g., van Kleef et al. 2005, van Trijp and van der Lans 2007, Huang and Lu 2016) of functional foods.

Although various studies have shown that public awareness of diet-related health information and other types of labeling policies can affect consumption patterns, empirical analyses of the effectiveness of specific health claims on increasing the demand for healthier foods (or decreasing the demand for unhealthy foods) has not been adequately addressed. Much attention has been paid to the healthiness of including fats and meats in diets, especially in richer countries where the consumption of these products tends to be higher (e.g., Heart Foundation 2021, CDC 2021). The United States Food and Drug Administration (FDA) issued a health claim in 1993 entitled Dietary Saturated Fat and Cholesterol and Risk of Coronary Heart Disease that provided consumers with scientificallyderived information on the healthiness of consuming these products. The objective of this study is to estimate how the demand for various fats and meats in the United States has been affected by this specific health claim.

\section{Functional Foods \& Health Claims}

The United States Food and Drug Administration (FDA) under the Federal Food, Drug and Cosmetic Act (FDA 2016a, Hobbs et al. 2014b) regulate health claims in the United States ${ }^{1}$. There are three methods for approving new disease risk reduction claims (referred to as 'health claims'). The first method is for fully endorsed NLEA (Nutrition Labeling and Education Act) health claims, which requires the highest level of scientific substantiation prior to approval. The second method is for 'FDAMA (FDA Modernization Act) health claims', which do not require an in-depth review by the FDA but must be based on authoritative statements made by the National Academy of Sciences or certain scientific

\footnotetext{
${ }^{1}$ The FDA defines three types of claims that can be made on foods. Those claims are defined as 1) structure/function claims, 2) health claims, and 3) nutrient content claims. First, structure/ function claims are defined as a statement that refers to the effects of a food or dietary supplement on the normal functioning of the body (FDA 2016b). Second, the FDA defines health claims as statements that indicate a relationship between a food, food constituent, or dietary supplement and the risk of a disease (FDA 2016b). Last, the FDA defines nutrient content claims as claims that describe the quantity or presence of nutrients in a food or dietary supplement (FDA 2016b, FDA 2005).
} 
departments of the United States government. The third method involves the use of 'qualified health claims'. Qualified health claims have significantly reduced the time it takes to get new disease risk reduction claims approved as they require far less robust scientific substantiation to support the claim. NLEA, FDAMA, and qualified health claims also are generic; manufacturers do not need premarket authorization to use approved claims. The United States has approved 55 disease risk reduction claims by 2018, largely a result of the use of qualified health claims: 12 approved NLEA health claims (FDA 2018a), 5 approved FDAMA health claims (FDA 2018b), and 28 approved qualified health claims (FDA 2017). An overview of the disease risk reduction claims is provided in Appendix 1.

\section{Dietary Fats}

Dietary fats assist with absorption of certain vitamins and nutrients and provide energy to the body (American Heart Association 2017a). However, not all dietary fats are the same; some can have negative health consequences when consumed in excess. The main types of dietary fats are: saturated fatty acids (SFAs), trans fatty acids (TFAs), monounsaturated fatty acids, and polyunsaturated fatty acids (American Heart Association 2016a). Each type of dietary fat has different properties and impacts on blood cholesterol levels and overall health.

During the 1980s, research identified that high levels of SFAs in the diet are associated with increased levels of low density lipoprotein (LDL) or "bad" cholesterol (Schleifer 2012), a major risk factor for heart disease and stroke (American Heart Association 2017b).Animal products, such as beef, chicken, and pork, are primary sources of SFAs (American Heart Association 2017b). Public awareness of the deleterious consequences of consuming SFAs grew significantly in the 1990s due to extensive publicity both in scientifically-based journal articles and widespread media reports (Wansink and Cheney 2005).

Trans fatty acids (TFAs) are found naturally in small quantities in some animal products (e.g., meat and dairy products) (American Heart Association 2017c). They can also be created when liquid vegetable oils are converted to solid forms using an industrial partial hydrogenation process (American Heart Association 2017c, Ratnayake et al. 2007). During the 1990s, research revealed that the consumption of TFAs posed an even greater danger to health than SFAs due to their effects on total blood cholesterol (Resnik 2010). TFAs increase total blood cholesterol levels through an increase in "bad" (LDL) cholesterol and a reduction in "good" (HDL) cholesterol (Ratnayake et al. 2007).

The American Heart Association (2017c) noted that a lack of understanding about the negative health effects from consumption of TFAs contributed to a significant rise in its inclusion in processed foods during the 1980s and 1990s. Ratnayake et al. (2007) reported that TFAs accounted for 20 to 50\% of total fat contents found in various margarine brands during that time-period. However, recent changes to production of margarine have led it now recognized as containing "heart healthy" fats (American Heart Association 2017a). .

Mono- and polyunsaturated fats are regarded as "heart healthy" fats (American Heart Association 2016b, 2017a) that reduce levels of LDL (bad) 
cholesterol, which lowers the risk of heart disease and stroke. They also provide essential nutrients and antioxidants to the body. Polyunsaturated fats provide omega- 3 and omega- 6 fatty acids; these are fats that cannot be produced by the body but are crucial for maintaining good health (American Heart Association 2016b). Vegetable oils, such as olive oil, canola oil, peanut oil, and safflower oil are high in monounsaturated fats (American Heart Association 2017a). Soybean oil, corn oil, and sunflower oil are high in polyunsaturated fats (American Heart Association 2016b).

In recent years, significant efforts have been made by public health officials to drastically reduce the consumption of both TFAs and SFAs to mitigate the rising economic burden of heart disease and related illnesses such as high cholesterol, high blood pressure, and stroke.

Previous research has found that belief and credibility in the health benefits of functional foods are the most important factors for consumer acceptance (Urala and Lähteenmäki 2004, Verbeke 2005, van Kleef et al. 2005). Further, the use of health claims can significantly improve acceptance rates and understanding of the health benefits (van Kleef et al. 2005, van Trijp and van der Lans 2007, Chrysochou and Grunert 2014, Huang and $\mathrm{Lu}$ 2016). However, the format and delivery of health claims (van Kleef et al. 2005, van Trijp and van der Lans 2007) as well as familiarity and personal relevance with the claimed benefit (Peng et al. 2006, Ding et al. 2015) play an important role in shaping consumers' understanding and acceptance.

The demand literature indicates that consumers adjust their dietary patterns in response to awareness of health information obtained from non-advertising sources. A health information index that accounts for the number of related published journal articles over the period is typically used as a proxy for awareness of health information (e.g., Brown and Schrader 1990, Capps and Schmitz 1991, Nichele 2003, Adhikari et al. 2006, Adhikari et al. 2007, Chang and Kinnucan 1991, Boetel and Lui 2003, Tonsor et al. 2010, Xiong et al. 2014). Evidence from a number of studies indicates that an increase in available health information (nonadvertising sources) regarding the negative health impacts of consuming foods that are high in saturated fats (such as butter and beef) decreased the demand for these foods (e.g., Brown and Schrader 1990, Capps and Schmitz 1991, Chang and Kinnucan 1991, Nichele 2003, Boetel and Liu 2003, Adhikari et al. 2006, Tonsor et al. 2010). Also, an increase in this type of health information increased the demand for foods lower in saturated fats (e.g., salad oils and fish) (e.g., Capps and Schmitz 1991, Boetel and Liu 2003, Nichele 2003, Tonsor et al. 2010).

It has been found that certain labelling policies can increase the demand for healthy foods (Mathios 2000, Tiesl et al. 2001, Dedah et al. 2011). Previous research on nutrition and health labelling policies has focused on the use of retail scanner data that records the prices and quantities of goods sold in grocery stores using point-of-sale systems. The literature indicates that the introduction of mandatory NLEA (Nutrition Labelling and Education Act) labelling policies in the United States reduced the market share of previously unlabeled salad dressings between 2.2 and $3.1 \%$ with high fat salad dressings having the largest decrease (Mathios 2000). Further, nutrient content claims provided on shelf tags in grocery 
stores were found to increase the demand for milk by $13 \%$, cream cheese by $9 \%$, and refried beans by $50 \%$ compared to conventional versions that did not have the nutrient content claims on shelf tags (Tiesl et al. 2001).

In general, the literature on acceptance of functional foods and the demand for foods indicated that consumers consider information from various sources when making dietary decisions. However, the current literature has not specifically examined the impacts of information provided in health claims on the demand for foods. Hence, the contribution of this study will be to empirically evaluate the efficacy of a current health claim in the United States at influencing demand of fats and meats.

\section{Empirical Analysis}

The health claim, "Dietary Saturated Fat and Cholesterol and Risk of Coronary Heart Disease (1993)" is analyzed for its impacts on food demand and population health in the United States. Two demand systems are estimated, based on available datasets.

The first system is the demand for fats, which includes three share equations for butter, margarine and lard. A binary variable (HC) has been included which takes the value of 0 before the approval of the health claim related to dietary fats and heart disease in 1993 and 1 thereafter.

It is expected that the "Dietary Saturated Fat and Cholesterol and Risk of Coronary Heart Disease (1993)" claim has negatively affected butter and lard demand due to their high saturated fat contents and positively affected demand for margarine. At the time of approval of this claim, the significant adverse impacts of TFAs were not as well understood as SFAs. It is expected that when this claim was approved in the United States (1993), consumers might have viewed margarine as a better choice than other types of fat due to greater concerns and awareness about saturated fats.

The second system analyzed is the demand for meats, which includes three share equations for poultry, pork and beef. The budget share for poultry is expected to be positively impacted due to low levels of saturated fat while beef and pork share equations are expected to show negative effects due to higher levels of saturated fat content.

\section{Data}

Per capita annual domestic disappearance data on a retail weight basis was used as a proxy for annual per capita consumption of fats and meats in the United States. Domestic disappearance data for fats was obtained from Economic Research Services (ERS), United States Department of Agriculture's Oil Crops Yearbooks for the years 1974 to 2016.

Per capita domestic disappearance data for poultry, pork, and beef in the meat demand system was obtained from the ERS (2017a) for the years 1970 to 2016. The per capita quantity of poultry is calculated as the sum of chicken, broilers, and 
turkey on an eviscerated weight basis. The per capita quantity of beef is calculated as the sum of beef and veal on a retail weight basis. The per capita quantity of pork is obtained on a retail weight basis.

Based on the best available dataset, average retail prices of margarine, lard, and fat in the United States from 1970 to 2016 are used for analysis. The average retail price of margarine was obtained from BLS (2017a). The price of margarine was missing for the years 1997 to 1999 . Since observations already were limited and the price did not vary much over those years, the price of 1996 was used for 1997 and the price of 2000 for 1999. For 1998, the average price of 1996 and 2000 was used. Average retail price of lard was obtained from ERS (2017c). Average retail price data for butter was obtained from ERS (2017d).

The United States consumer price indices for poultry, pork and beef are used to proxy for prices from 1970 to 2016. The CPI for poultry is obtained from BLS (2017b), the CPI for pork is obtained from BLS (2017c) and lastly, the CPI for beef is obtained from BLS (2017d). A summary of the descriptions and sources for all data used in this study is provided in Appendix 2.

\section{Empirical Results}

The linear approximate almost ideal demand system (LA/AIDS) is used as the functional form for all the estimated demand systems. Zellner's iterative seemingly unrelated regressions (ITSUR) is used to estimate the demand for the products in each system and the theoretical conditions of homogeneity, symmetry and addingup are imposed in the models ${ }^{2}$.

\section{The Demand for Fats in the United States}

The annual per capita consumption of margarine has steadily declined while that for butter and lard also have declined but remained relatively constant from 1984 to 2010 (Figure 1) (ERS 2017a).

The coefficient estimates for the demand for fats in the United States from 1984 to 2010 are shown in Table 1. The share equation for butter has an $\mathrm{R}^{2}$ of 0.947. The results for the butter share equation show that butter's own-price and the price of margarine are statistically significant at the $1 \%$ level. The health claim variable is significant at the $1 \%$ level and indicates that, on average, the demand for butter was 7.1\% lower after the approval of the "Dietary Saturated Fat and Cholesterol and Risk of Coronary Heart Disease" claim in 1993. In addition, the

\footnotetext{
${ }^{2}$ The SUR approach is used to estimate a series of separate equations as a system rather than individually due to the assumption that there is correlation among the random error terms that should be considered during estimation to improve statistical inference. The Breusch-Pagan (BP) test of independence is a test used to evaluate the appropriateness of SUR estimation by testing for correlation among the residuals in the share equations. If the null hypothesis that the correlation among the errors is zero is rejected, then SUR is an appropriate estimation method (Wooldridge 2010). Based on the results of the BP tests, all systems showed correlation among the error terms of each equation and are estimated using seemingly unrelated regressions.
} 
time trend is significant at the $1 \%$ level and indicates that the demand for butter has increased an average of $1.31 \%$ per year over the sample period.

Figure 1. Per Capita Consumption of Fats in the United States (1984-2010)

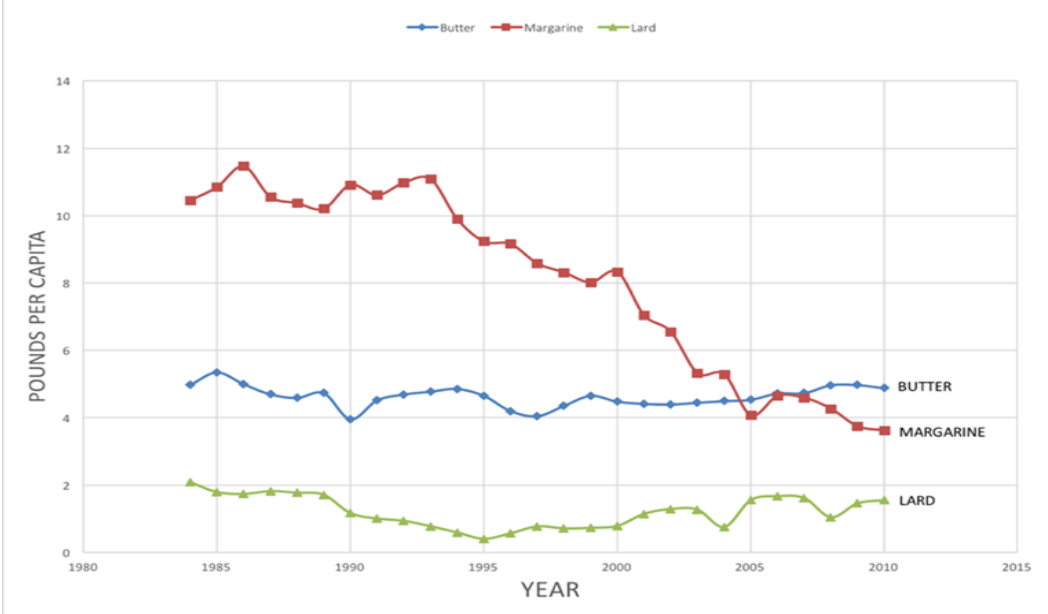

Source: ERS (2017a).

Table 1. Coefficient Estimates - Demand for Fats in the United States

\begin{tabular}{|l|c|c|c|}
\hline & \multicolumn{3}{|c|}{ Share Equation } \\
\hline $\begin{array}{l}\text { Independent } \\
\text { Variables }\end{array}$ & Butter & Margarine & Lard \\
\hline Butter Price & $0.244^{* * *}$ & $-0.243^{* * *}$ & -0.001 \\
\hline & $(0.028)$ & $(0.030)$ & $(0.003)$ \\
\hline Margarine Price & $-0.243^{* * *}$ & $0.253^{* * *}$ & $-0.010^{* *}$ \\
\hline & $(0.030)$ & $(0.033)$ & $(0.004)$ \\
\hline Lard Price & -0.001 & $-0.010^{* *}$ & $0.011^{* * *}$ \\
\hline & $(0.003)$ & $(0.004)$ & $(0.002)$ \\
\hline Expenditure & -0.079 & 0.083 & -0.004 \\
\hline & $(0.152)$ & $(0.167)$ & $(0.019)$ \\
\hline HC1993 & $-0.0710 * * *$ & $0.0850^{* * *}$ & $-0.0141^{* * *}$ \\
\hline & $(0.026)$ & $(0.029)$ & $(0.003)$ \\
\hline Time & $0.0131 * * *$ & $-0.0138 * * *$ & $0.00073 * * *$ \\
\hline & $(0.002)$ & $(0.002)$ & $(0.0002)$ \\
\hline Constant & 0.566 & 0.387 & 0.047 \\
\hline & $(0.681)$ & $(0.746)$ & $(0.086)$ \\
\hline Observations & 27 & 27 & 0.656 \\
\hline R-squared & 0.947 & 0.94 & \\
\hline
\end{tabular}

Standard errors reported in parentheses.

Significance at $* * * 1 \%, * * 5 \%, * 10 \%$ level.

Source: Authors.

Next, the share equation for margarine has an $\mathrm{R}^{2}$ of 0.94 . The results show that the price of margarine and butter, and lard are significant at the $1 \%$ and $5 \%$ levels. In addition, the health claim variable is significant at the $1 \%$ level and indicates that, on average, the demand for margarine was $8.50 \%$ greater after the approval of the health claim in 1993. The time trend is also significant at the $1 \%$ 
level and indicates that margarine demand fell by an average of $1.38 \%$ per year over the sample period.

Last, the share equation for lard has an $\mathrm{R}^{2}$ of 0.656 . The results from the lard equation show that the price of lard, and margarine are significant at the $1 \%$ and $5 \%$ level, respectively. The health claim variable is also significant at the $1 \%$ level and indicates that the demand for lard was, on average, $1.41 \%$ lower after the approval of the health claim in 1993. In addition, the time trend is significant at the $1 \%$ level and indicates that the demand for lard increased by approximately $0.073 \%$ per year over the sample period.

The results of the "Dietary Saturated Fat and Cholesterol and Risk of Coronary Heart Disease (1993)" health claim on the demand for butter, margarine, and lard in the United States were as expected. After the approval in 1993, the demand for butter decreased $(7.1 \%)$, the demand for margarine increased $(8.50 \%)$, and the demand for lard decreased (1.41\%). The "Dietary Saturated Fat and Cholesterol and Risk of Coronary Heart Disease" health claim describes the adverse health effects of saturated fats on cholesterol and the risk of heart disease. Therefore, it makes sense that consumers would respond to this type of health information by decreasing the demand for butter and lard, which are high in saturated fats. In addition, during the early 1990s, there was considerable published research and media attention about the link between saturated fats and heart disease that could have contributed to the success of this health claim.

The positive impacts on the demand for margarine after the approval of the "Dietary Saturated Fat and Cholesterol and Risk of Coronary Heart Disease (1993)" also make sense. During the 1980s and 1990s, manufacturers increasingly used trans fats as a replacement for saturated fats in margarine to make them a lower saturated fat alternative. While trans fats are now known to have significant adverse effects on health, the health implications of trans fats were not yet fully understood at the time of approval of the "Dietary Saturated Fat and Cholesterol and Risk of Coronary Heart Disease (1993)" health claim. Therefore, it makes sense that, in 1993, consumers would respond to advice about saturated fats with an increase in the demand of an alternative lower saturated fat option, in this case, margarine.

In addition, the results from the trend variables also make sense. It appears that consumers have adjusted their demand for butter ( $1.31 \%$ increase per year), margarine (1.38\% decrease per year), and lard ( $0.073 \%$ increase per year) over the whole sample period to reflect the significant changes in the understanding of the role of different dietary fats on health. Specifically, the realization that trans fats have even more severe health consequences than saturated fats is captured by the decrease in margarine demand over time. The increase in butter and lard demand over time might be a result of improved understanding by consumers of the consequences of trans fats, leading to higher consumption of butter.

The elasticity estimates for the demand for fats in the United States are presented in Table 2. The own-price elasticities for butter (-0.487), margarine $(-0.489)$, and lard (-0.104) are all inelastic. In addition, the cross-price elasticities for the price of margarine with respect to butter demand (-0.373) and vice versa $(-0.680)$ indicates a complementary relationship. In the margarine share equation, 
the cross-price elasticity for the price of lard is -0.025 , also indicating a complementary relationship. In the lard share equation, cross-price elasticities indicate butter (0.105) is a substitute for lard and margarine (-0.676) is a complement for lard. Last, the expenditure elasticities indicate that butter (0.860), margarine (1.194), and lard (0.679) are normal goods with margarine slightly income elastic and butter and lard income inelastic.

Table 2. Elasticity Estimates - Fats in the United States

\begin{tabular}{|l|c|c|c|}
\hline & \multicolumn{3}{|c|}{ Share Equation } \\
\hline Butter Price & Butter & Margarine & Lard \\
\hline & $-0.487 * * *$ & $-0.680^{* * *}$ & 0.105 \\
\hline Margarine Price & $(0.129)$ & $(0.265)$ & $(0.947)$ \\
\hline & $-0.373 * * *$ & $-0.489 * *$ & -0.676 \\
\hline Lard Price & $(0.090)$ & $(0.222)$ & $(1.074)$ \\
\hline & 0.0001 & $-0.025 * *$ & -0.104 \\
\hline Expenditure & $(0.007)$ & $(0.011)$ & $(0.181)$ \\
\hline & $0.860 * * *$ & $1.194 * * *$ & 0.679 \\
\hline
\end{tabular}

Standard errors reported in parentheses.

Significance at $* * * 1 \%, * * 5 \%, * 10 \%$ level.

Source: Authors.

The inelastic own-price elasticities and expenditure elasticities were not surprising as they are consistent with previous findings in the literature. Chang and Kinnucan (1991) also found inelastic own-prices for butter (-0.74), margarine (0.09), and shortening (-0.29). Goddard and Amuah (1989) found butter to be income elastic (1.18) and margarine to be income inelastic (0.84). Goddard and Amuah (1989) also found an overall complementary relationship between butter and margarine (cross-price elasticities of -0.26 and -0.29) using uncompensated price elasticities. The complementary relationship between butter and margarine was somewhat unexpected. However, it might reflect different nutritional properties, consistencies, and flavors between butter and margarine that might contribute to reasons why they are not viewed as appropriate substitutes for each other.

\section{The Demand for Meat in the United States}

The annual per capita consumption of poultry, pork and beef in the United States has changed significantly since the 1970s (Figure 2): poultry consumption has increased significantly while beef consumption has declined. In contrast, per capital pork consumption has remained relatively constant compared to poultry and beef consumption. Again, these results make sense given the changes in the understanding of dietary fats and health that occurred over the period.

Figure 2. Per Capital Consumption of Meats in the United States (1970-2016) 


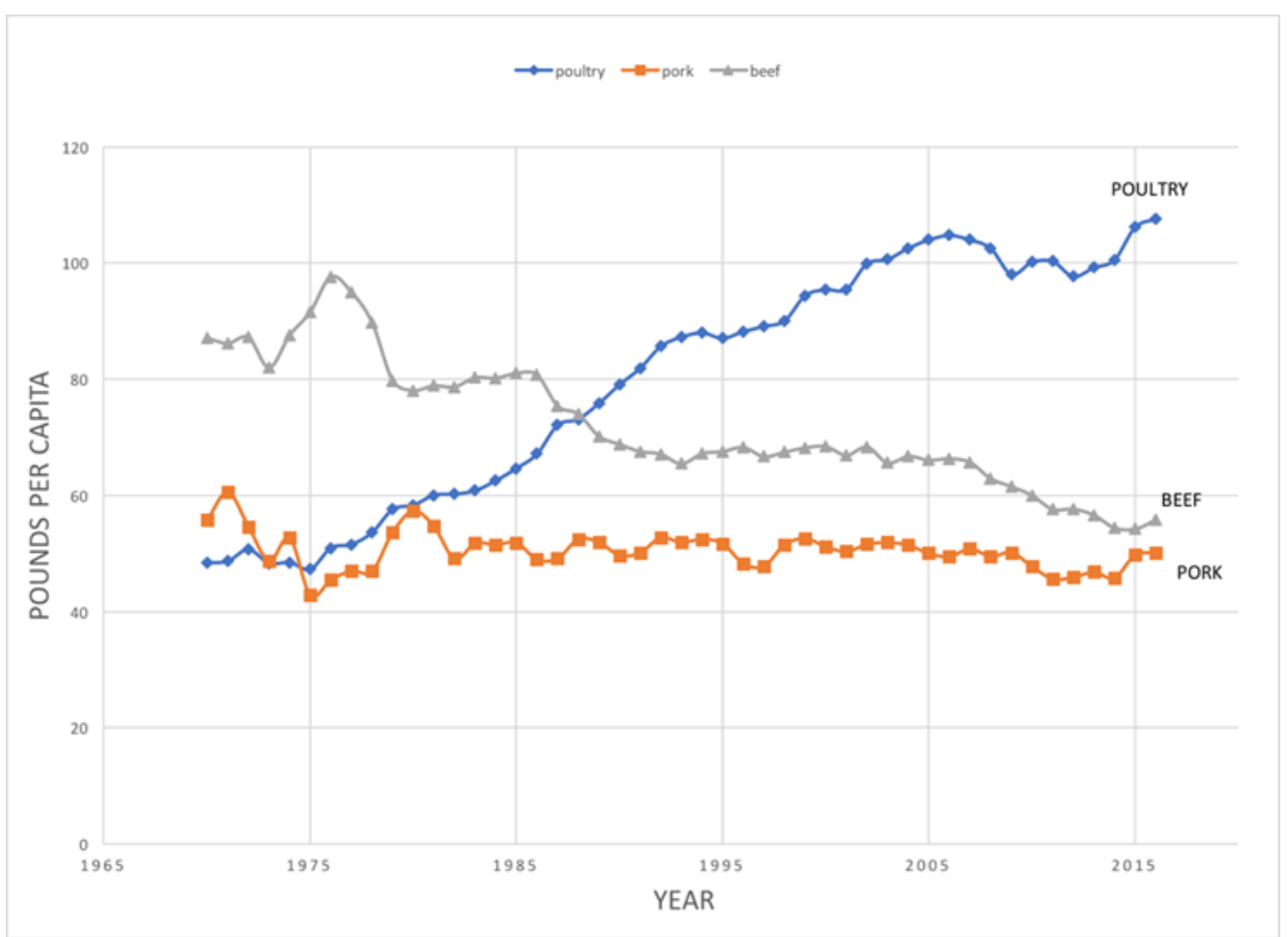

Source: ERS (2017b).

The coefficient estimates for the demand for meats in the United States from 1970 to 2016 are shown in Table 3 . The poultry share equation has an $R^{2}$ of 0.966 . The results for the poultry share equation indicate that the price of poultry, pork, and beef and the expenditure variable are significant at the $1 \%$ level. The health claim variable is statistically significant at the $5 \%$ level and indicates that the demand for poultry was, on average, $1.95 \%$ greater after the approval of the "Dietary Saturated Fat and Cholesterol and Risk of Coronary Heart Disease" health claim in 1993.

The $\mathrm{R}^{2}$ for the pork share equation is 0.947 . The results from the pork share equation show that pork's own-price and the price of poultry are statistically significant at the $1 \%$ level. In addition, the time trend is significant at the $1 \%$ level and indicates that, on average, the demand for pork decreased by $0.24 \%$ per year over the sample period.

The $\mathrm{R}^{2}$ for the beef share equation is 0.905 . The results from the beef share equation show that beef's own-price, the price of poultry, and the expenditure variable are significant at the $1 \%$ level. Additionally, the health claim variable in the beef share equation is significant at the $5 \%$ level, which indicates that after the approval of the "Dietary Saturated Fat and Cholesterol and Risk of Coronary Heart Disease" health claim in 1993 the demand for beef was, on average, 2.42\% lower than before the approval.

Table 3. Coefficient Estimates - Demand for Meats in the United States

\begin{tabular}{|l|c|c|c|}
\hline & \multicolumn{3}{|c|}{ Share Equation } \\
\hline $\begin{array}{l}\text { Independent } \\
\text { Variables }\end{array}$ & Poultry & Pork & Beef \\
\hline Poultry Price & $0.216^{* * *}$ & $-0.052^{* * *}$ & $-0.164^{* * *}$ \\
\hline
\end{tabular}




\begin{tabular}{|l|c|c|c|}
\hline & $(0.027)$ & $(0.015)$ & $(0.026)$ \\
\hline Pork Price & $-0.052^{* * *}$ & $0.050^{* * *}$ & 0.002 \\
\hline & $(0.015)$ & $(0.012)$ & $(0.010)$ \\
\hline Beef Price & $-0.164^{* * *}$ & 0.002 & $0.162^{* * *}$ \\
\hline & $(0.026)$ & $(0.010)$ & $(0.031)$ \\
\hline Expenditure & $0.148^{* * *}$ & 0.018 & $-0.166^{* * *}$ \\
\hline & $(0.030)$ & $(0.013)$ & $(0.036)$ \\
\hline HC1993 & $0.0195^{* *}$ & 0.0047 & $-0.0242^{* *}$ \\
\hline & $(0.009)$ & $(0.004)$ & $(0.011)$ \\
\hline Time & 0.0014 & $-0.0024^{* * *}$ & 0.001 \\
\hline & $(0.001)$ & $(0.0004)$ & $(0.001)$ \\
\hline Constant & $-0.924^{* * *}$ & 0.146 & $1.779^{* * *}$ \\
\hline & $(0.238)$ & $(0.103)$ & $(0.285)$ \\
\hline Observations & 47 & 47 & 47 \\
\hline R-squared & 0.966 & 0.947 & 0.905 \\
\hline
\end{tabular}

Standard errors reported in parentheses.

Significance at $* * * 1 \%, * * 5 \%, * 10 \%$ level.

Source: Authors.

The impacts of the "Dietary Saturated Fat and Cholesterol and Risk of Coronary Heart Disease" health claim on poultry (1.95\% increase) and beef ( $2.42 \%$ decrease) demand were as expected and make sense considering poultry is a relatively low source of saturated fats and beef is a relatively higher source (American Heart Association 2017a). In addition, there was a large volume of published research on the impacts of saturated fats and related media attention around the time of this claim (Wansink and Cheney 2005) that likely contributed to the success of this health claim in terms of reducing the consumption of foods higher in saturated fats.

Table 4. Elasticity Estimates - Meats in the United States

\begin{tabular}{|l|c|c|c|}
\hline & \multicolumn{3}{|c|}{ Share Equation } \\
\hline Variables & Poultry & Pork & Beef \\
\hline Poultry Price & $-0.606^{* * *}$ & $-0.243^{* * *}$ & $-0.273^{* * *}$ \\
\hline Pork Price & $(0.074)$ & $(0.074)$ & $(0.079)$ \\
\hline & $-0.220^{* * *}$ & $-0.813^{* * *}$ & $0.118^{* * *}$ \\
\hline Beef Price & $(0.040)$ & $(0.056)$ & $(0.037)$ \\
\hline & $-0.545^{* * *}$ & -0.019 & $-0.383^{* * *}$ \\
\hline Expenditure & $(0.073)$ & $(0.053)$ & $(0.089)$ \\
\hline & $1.372^{* * *}$ & $1.075^{* * *}$ & $0.538^{* * *}$ \\
\hline
\end{tabular}

Standard errors reported in parentheses.

Significance at $* * * 1 \%, * * 5 \%, * 10 \%$ level.

Source: Authors.

The price and expenditure elasticity estimates are reported in Table 4. All own-price elasticities are inelastic for poultry (-0.606), pork (-0.813), and beef ($0.383)$. The cross-price elasticities, poultry, pork, and beef are all complements to each other except for pork, which is a substitute in the beef share equation. As for the expenditure elasticities, all are positive, indicating poultry (1.372), pork 
(1.075), and beef (0.538) are normal goods and that poultry and pork are income elastic while beef is income inelastic.

The elasticity estimates found in this study are not surprising. The literature typically reports inelastic own-prices and, although there does not appear to be a consensus on which meats are substitutes, the literature typically finds that at least one meat is a substitute to another. In that regard, consistent with the results found here, Brester and Schroeder (1995) also found that poultry (-0.33), pork (-0.69), and beef (-0.56) are own-price inelastic in the United States from 1970 to 1993 and that pork shows the greatest own-price sensitivity relative to poultry and beef. Similarly, Tonsor et al. (2010) found poultry (-0.099), pork (-0.7396), and beef ($0.4199)$ are own-price inelastic and that pork is most sensitive to own-prices in the United States from 1982 to 2007.

Tonsor et al. (2010) also found that poultry and beef are gross complements. The cross-price elasticities for the price of poultry on beef demand is -0.0406 and the price of beef on poultry demand is -0.1113 . Similarly, Kinnucan et al. (1997) also found that pork and poultry are complements in the United States from 1976 to 1993. In contrast to the results presented here, Tonsor et al. (2010) found that pork and beef are gross substitutes (0.0163 and 0.0269) while the results here show that beef is a substitute only in the pork equation but not vice versa.

The fact that United States consumers were found to allocate more expenditures towards poultry (1.372) than pork (1.075) and beef (0.538) makes sense because of the negative health aspects of consuming too much red meat due to higher saturated fat and cholesterol levels. In addition, previous research has found similar income elasticities. Adhikari et al. (2006) also found that poultry (1.020) and pork (1.880) are income elastic and that beef (0.404) is income inelastic in the United States using data from 1989 to 2003. In addition, Kinnucan, et al. (1997) found that pork is income elastic (1.005) and beef is income inelastic (0.999) in the United States from 1976 to 1993.

\section{Summary of Findings}

The results from the demand analysis showed that the "Dietary Saturated Fat and Cholesterol and Risk of Coronary Heart Disease (1993)" health claim was successful at influencing the consumption of a healthier diet in the United States Statistically significant findings indicate that the demand for butter $(7.10 \%)$, lard $(1.41 \%)$, and beef $(2.42 \%)$ - products that have relatively higher contents of saturated fats - decreased after the approval of the health claim in 1993. In contrast, the demand for margarine $(8.50 \%)$, which was thought to be a better option during the early 1990s because of reduced saturated fat contents, and poultry $(1.95 \%)$ increased after the approval of the United States health claim in 1993. In addition, consumers showed significant changes in consumption patterns over time. The demand for pork fell on average by $0.24 \%$ and, consistent with the findings that TFAs have serious health consequences, the demand for margarine showed the largest annual decrease of $1.38 \%$ per year. The demand for butter $(1.31 \%)$ and lard $(0.073 \%)$ increased slightly over the period, which might also reflect changes due to the increased knowledge of the impacts of TFA consumption. 
Additionally, the demand analysis revealed important price and expenditure effects. Own-price elasticities for butter (-0.487), margarine (-0.489), and lard $(-0.104)$ were inelastic and consistent with previous findings. Demand for poultry $(-0.606)$, pork $(-0.813)$, and beef $(-0.383)$ were found to be inelastic, which was consistent with previous literature, and all meats were found to be gross complements. Like the findings in this study, a small number of previous findings also have shown gross complementary relationships among poultry, pork and beef. However, more typically, at least one meat is found to be substitute for another. Some studies find pork and beef are substitutes while others find pork and chicken to be substitutes. Also, consistent with previous findings, poultry was most sensitive to change in income (1.372) followed by pork (1.075) and then beef (0.538).

\section{Policy Implications \& Recommendations to Further Improve Health Claims' Efficacy}

\section{Policy Implications}

Research has found that many chronic illnesses are preventable and that the risk of chronic disease can be reduced significantly through the adoption of a healthy lifestyle, which includes a balanced and nutritious diet (CDC 2016, Ippolito and Mathios 1991, Thompson and Moughan 2008, WHO 2003). These illnesses, and many more, place substantial economic burden on society due to the direct public healthcare costs, such as the hospital expenditures and pharmaceutical expenditures, associated with them (Public Health Agency of Canada 2014). In addition, there are considerable indirect costs associated with a loss of productivity and costs that cannot be measured, such as reduction in the quality of life and wellbeing due to the suffering caused by illness.

A second reason the "Dietary Saturated Fat and Cholesterol and Risk of Coronary Heart Disease (1993)" might have been more successful is that there was significant media attention on the issue of dietary fats and heart disease during the 1990s (Wansink and Cheney 2005). It is likely that this media attention facilitated greater consumer awareness and understanding about this health issue.

\section{Conclusion}

Overall, the empirical results suggest that the health claim "Dietary Saturated Fat and Cholesterol and Risk of Coronary Heart Disease (1993)" has been effective at changing the demand for fats and meats in the United States and improvements in dietary patterns have coincided with better health outcomes. The empirical results indicate that the health claim was effective at encouraging the consumption of a healthier diet that was lower in saturated fats in the United States. The demand for foods relatively higher in saturated fats decreased after the approval of the health claim in 1993 while the demand for foods lower in saturated fats increased. 
Specifically, statistically significant results indicated that butter $(7.10 \%)$, lard $(1.41 \%)$, and beef $(2.42 \%)$ demand decreased while margarine $(8.50 \%)$ and poultry $(1.95 \%)$ increased after the approval of the United States health claim in 1993.

Consumers in the United States showed changes in consumption choices over time. On average, the demand for pork $(0.24 \% /$ year $)$ and margarine $(1.38 \% / y e a r)$ decreased over the period while the demand for butter $(1.31 \% / y e a r)$ and lard $(0.073 \% / y e a r)$ increased over the period. Although butter and lard are higher in saturated fats, the increase likely represents adjustments in consumption due to changes in awareness of the relatively more severe negative health consequences of trans fats compared to saturated fats.

Overall, the results from this study suggest that the United States "Dietary Saturated Fat and Cholesterol and Risk of Coronary Heart Disease (1993)" health claim was successful at influencing consumption patterns of fats and meats in the United States.

\section{Limitations of the Study}

This study provides several key insights into the effectiveness of a current health claim at influencing consumption patterns and fostering healthy dietary behaviors. However, a few limitations of the study should be noted as they provide opportunity for improvements in future research. In that regard, the use of aggregated data might not provide sufficient variation to fully analyze the extent at which a specific health claim influences food demand. Further, the current study examines the effects of a health claim on a particular subset of foods; however, there is a possibility for substitution across larger subsets. There is also the potential for additional factors, outside the scope of this study, to influence food demand (e.g., demographic variables, other types of external health information, preference fluctuations, advertising and promotions). More robust results might be achieved with a different of model specification and richer dataset, such as survey or market data.

While these limitations are important for analyzing the effects of current health claims on the demand for fats and oils and meats, data were not available to systematically investigate all the factors associated with changes in food demand. As more data becomes available, the current analysis can be fine-tuned to provide a more comprehensive interpretation of the scope of health claims at influencing dietary behaviors. Understanding the efficacy of health policies aimed at improving dietary patterns and associated public health outcomes is essential given the rising incidence of diet-related chronic illness and related economic burdens in the United States.

\section{References}

Adhikari M, Paudel L, Houston JE, Paudel KP, Bukenya J (2006) The impact of cholesterol information on meat demand: application of an updated cholesterol index. Journal of Food Distribution Research 37(2): 60-69. 
Adhikari M, Paudel L, Paudel K, Houston JE, Bukenya J (2007) Impact of low carbohydrate information on vegetable demands in the United States. Applied Economics Letters 14(13): 939-944.

American Heart Association (2016a) Dietary fats. American Heart Association.

American Heart Association (2016b) Polyunsaturated fats. American Heart Association.

American Heart Association (2017a) Monounsaturated fats. American Heart Association.

American Heart Association (2017b) Saturated fats. American Heart Association.

American Heart Association (2017c) Trans fats. American Heart Association.

Aschemann-Witzel J (2011) The EU health claim regulation in international comparison: Review of the possible impact on food marketing and consumer protection. $C A B$ Reviews: Perspectives in Agriculture, Veterinary Science, Nutrition and Natural Resources 6(33): 1-7.

Boetel, Brenda L., and Donald J. Liu. 2003. Evaluating the effect of generic advertising and food health information within a meat demand system. Agribusiness 19 (3): 34554.

Brester GW, Schroeder TC (1995) The impacts of brand and generic advertising on meat demand. American Journal of Agricultural Economics 77(4): 969-979.

Brown DJ, Schrader LF (1990) Cholesterol information and shell egg consumption. American Journal of Agricultural Economics 72(3): 548-555.

Bureau of Labor Statistics - BLS (2017a) Series ID APU000716114 - Margarine, stick, per lb. (453.6 gm) in U.S. city average, average price, not seasonally adjusted. Occupational Employment Statistics.

Bureau of Labor Statistics - BLS (2017b) Series ID CUUROOOOSEFF - Poultry in U.S. city average, all urban consumers, not seasonally adjusted. Occupational Employment Statistics.

Bureau of Labor Statistics - BLS (2017c) Series ID CUURO000SEFD - Pork in U.S. city average, all urban consumers, not seasonally adjusted. Occupational Employment Statistics.

Bureau of Labor Statistics - BLS (2017d) Series ID CUUROOOOSEFC - Beef and veal in U.S. city average, all urban consumers, not seasonally adjusted. Occupational Employment Statistics.

Canada Food Inspection Agency - CFIA (2016) Health claims. Canada Food Inspection Agency.

Capps O, Schmitz JD (1991) A recognition of health and nutrition factors in food demand analysis. Western Journal of Agricultural Economics 16(1): 21-35.

Centers for Disease Control and Prevention - CDC (2016) Heart disease fact sheet. Centers for Disease Control and Prevention.

Centers for Disease Control and Prevention - CDC (2017) Chronic disease overview. Centers for Disease Control and Prevention.

Centers for Disease Control and Prevention - CDC (2021) Healthy eating for a healthy weight. Centers for Disease Control and Prevention.

Chang H-S, Kinnucan HW (1991) Advertising, information, and product quality: the case of butter. American Journal of Agricultural Economics 73(4): 1195-1203.

Chrysochou P, Grunert KG (2014) Health-related ad information and health motivation effects on product evaluations. Journal of Business Research 67(6): 1209-1217.

Dedah C, Keithly WR, Kazmierczak RF (2011) An analysis of US oyster demand and the influence of labeling requirements. Marine Resource Economics 26(1): 17-33.

Dietz WH, Douglas CE, Brownson RC (2016) Chronic disease prevention: tobacco avoidance, physical activity, and nutrition for a healthy start. Jama 316(16): 16451656. 
Ding YL, Veeman MM, Adamowicz WL (2015) Functional food choices: impacts of trust and health control beliefs on Canadian consumers' choices of canola oil. Food Policy 52(C): 92-98.

Economic Research Services - ERS (2017a) Food availability (per capita) data system. Economic Research Services.

Economic Research Services - ERS (2017b) Table 40 - Margarine (actual weight): supply and disappearance, U.S., 1980-2010. Oil Crops Yearbooks. Economic Research Services.

Economic Research Services - ERS (2017c) Table 42--Lard: supply, disappearance, and price, U.S., 1980-2016. Oil Crops Yearbooks. Economic Research Services.

Economic Research Services - ERS (2017d) Table 43--Butter (actual weight): supply, disappearance, and price, U.S., 1980-2016. Oil Crops Yearbooks. Economic Research Services.

Goddard EW, Amuah AK (1989) The demand for Canadian fats and oils: a case study of advertising effectiveness. American Journal of Agricultural Economics 71(3): 741749.

Heart Foundation (2021) Fats, oils and heart health. Heart Foundation.

Herath D, Cranfield J, Henson S (2008) Who consumes functional foods and nutraceuticals in Canada? Results of cluster analysis of the 2006 survey of Canadians' Demand for Food Products Supporting Health and Wellness. Appetite 51(2): 256-265.

Hobbs JE, Malla S, Sogah EK (2014a) Regulatory frameworks for functional food and supplements. Canadian Journal of Agricultural Economics/Revue Canadienne d'Agroeconomie 62(4): 569-594.

Hobbs JE, Malla S, Sogah EK, Yeung MT (2014b) Regulating health foods: policy challenges and consumer conundrums. Cheltenham, UK: Edward Elgar Publishing Limited.

Huang L, Lu J (2016) The impact of package color and the nutrition content labels on the perception of food healthiness and purchase intention. Journal of Food Products Marketing 22(2): 191-218.

Ippolito PM, Mathios AD (1991) Health claims in food marketing: evidence on knowledge and behavior in the cereal market. Journal of Public Policy \& Marketing 10(1): 1532.

Kinnucan HW, Xiao H, Hsia C-J, Jackson JD (1997) Effects of health information and generic advertising on U.S. meat demand. American Journal of Agricultural Economics 79(1): 13-23.

Malla S, Hobbs JE, Sogah EK (2013) Functional foods and natural health products regulations in Canada and around the world: nutrition labels and health claims. Saskatoon, Saskatchewan, Canada: Report prepared for the Canadian Agricultural Innovation and Regulation Network.

Markosyan A, McCluskey JJ, Wahl TI (2009) Consumer response to information about a functional food product: apples enriched with antioxidants. Canadian Journal of Agricultural Economics 57(3): 325-341.

Mathios AD (2000) The impact of mandatory disclosure laws on product choices: an analysis of the salad dressing market. The Journal of Law \& Economics 43(2): 651678.

Milner JA (1999) Functional foods and health promotion. Journal of Nutrition 129(7): 1395S-7S.

Moors EHM (2012) Functional foods: regulation and innovations in the EU. Innovation: The European Journal of Social Science Research 25(4): 424-440. 
Nichele V (2003) Health information and food demand in France. In WS Chern, S Wen, K Rickertsen, Inc NetLibrary (eds.), Health, Nutrition and Food Demand. Wallingford, UK: CABI Pub.

Peng Y, West GE, Wang C (2006) Consumer attitudes and acceptance of CLA-enriched dairy products. Canadian Journal of Agricultural Economics/Revue Canadienne D'agroeconomie 54(4): 663-684.

Public Health Agency of Canada (2014) Economic burden of illness in Canada, 20052008. Catalogue HP50-1/2013E-PDF, Publication No. 130148. Public Health Agency of Canada.

Raghupathi W, Raghupathi V (2018) An empirical study of chronic diseases in the United States: a visual analytics approach to public health. International Journal of Environmental Research and Public Health 15(3): 431.

Ratnayake WMN, Gagnon C, Dumais L, Lillycrop W, Wong L, Meleta M, et al. (2007) Trans fatty acid content of Canadian margarines prior to mandatory trans-fat labelling. Journal of the American Oil Chemists' Society 84(9): 817-825.

Resnik D (2010) Trans-fat bans and human freedom. The American Journal of Bioethics 10(3): 27-32.

Schleifer D (2012) The perfect solution: how trans fats became the healthy replacement for saturated fats. Technology and Culture 53(1): 94-119.

Teisl MF, Bockstael NE, Levy A (2001) Measuring the welfare effects of nutrition information. American Journal of Agricultural Economics 83(1): 133-149.

Teratanavat R, Hooker NH (2006) Consumer valuations and preference heterogeneity for a novel functional food. Journal of Food Science 71(7): S533-41.

Thompson AK., Moughan PJ (2008) Innovation in the foods industry: functional foods. Innovation 10(1): 61-73.

Tonsor GT, Mintert JR, Schroeder TC (2010) U.S. meat demand: household dynamics and media information impacts. Journal of Agricultural and Resource Economics 35(1): $1-17$.

Urala N, Lähteenmäki L (2004) Attitudes behind consumers' willingness to use functional foods. Food Quality and Preference 15(7): 793-803.

U.S. Food and Drug Administration - FDA (2005) Dietary supplement labelling guide: chapter VI. Claims. U.S. Food and Drug Administration.

U.S. Food and Drug Administration - FDA (2013) Guidance for industry: a food labeling guide (9. Appendix A: definitions of nutrient content claims). U.S. Food and Drug Administration.

U.S. Food and Drug Administration - FDA (2016a) Dietary supplements. U.S. Food and Drug Administration.

U.S. Food and Drug Administration - FDA (2016b) Label claims for conventional foods and dietary supplements. U.S. Food and Drug Administration.

U.S. Food and Drug Administration - FDA (2017) Qualified health claims: letters of enforcement discretion. U.S. Food and Drug Administration.

U.S. Food and Drug Administration - FDA (2018a) Authorized health claims that meet the significant scientific agreement (SSA) Standard. U.S. Food and Drug Administration.

U.S. Food and Drug Administration - FDA (2018b) FDA modernization act (FDAMA) claims. U.S. Food and Drug Administration.

van Kleef E, van Trijp HCM, Luning P (2005) Functional foods: health claim-food product compatibility and the impact of health claim framing on consumer evaluation. Appetite 44(3): 299-308.

van Trijp HCM, van der Lans IA (2007) Consumer perceptions of nutrition and health claims. Appetite 48(3): 305-324. 
Veeman M (2002) Policy development for novel foods: issues and challenges for functional food. Canadian Journal of Agricultural Economics/Revue Canadienne d'agroeconomie 50(4): 527-539.

Verbeke W (2005) Consumer acceptance of functional foods: socio-demographic, cognitive and attitudinal determinants. Food quality and preference 16(1): 45-57.

Wansink B, Cheney MM (2005) Leveraging FDA health claims. Journal of Consumer Affairs 39(2): 386-398.

Wooldridge JM (2010) Econometric analysis of cross section and panel data. Massachusetts: MIT Press.

World Health Organization - WHO (2003) Diet, nutrition, and the prevention of chronic diseases: report of a joint WHO/FAO expert consultation. Volume 916. Geneva: World Health Organization.

Xiong B, Sumner D, Matthews W (2014) A new market for an old food: the U.S. demand for olive oil. Agricultural Economics 45(1): 107-118. 


\section{Appendix 1. United States Health and Nutrient Content Claims}

\section{NLEA Authorized Health Claims}

- Calcium, Vitamin D, and Osteoporosis (2008)

- Stanols/Sterols and Risk of Coronary Heart Disease (2000)

- Soy Protein and Risk of Coronary Heart Disease (1999)

- Soluble Fiber from Certain Foods and Risk of Coronary Heart Disease (1997)

- Dietary Non-cariogenic Carbohydrate Sweeteners and Dental Caries (1996)

- Folic Acid and Neural Tube Defects (1996)

- Dietary Lipids (Fat) and Cancer (1993)

- Dietary Saturated Fat and Cholesterol and Risk of Coronary Heart Disease (1993)

- Fiber-containing Grain Products, Fruits and Vegetables and Cancer (1993)

- Fruits and Vegetables and Cancer (1993)

- Fruits, Vegetables and Grain Products that contain Fiber, particularly Soluble fiber, and Risk of Coronary Heart Disease (1993)

- Sodium and Hypertension (1993)

Source: FDA (2018a).

\section{FDAMA Authorized Health Claims}

- Whole Grain Foods and Risk of Heart Disease and Certain Cancers

- Whole Grain Foods with Moderate Fat Content and Risk of Heart Disease

- Potassium and the Risk of High Blood Pressure and Stroke

- Fluoridated Water and Reduced Risk of Dental Carries

- Saturated Fat, Cholesterol, and Trans Fat, and Reduced Risk of Heart Disease Source: FDA (2018b).

\section{Qualified Health Claims}

- $100 \%$ Whey-Protein Partially Hydrolyzed Infant Formula and Reduced Risk of Atopic Dermatitis. May 24, 2011

- Green Tea and Risk of Breast Cancer and Prostate Cancer. February 24, 2011

- Selenium and a Reduced Risk of Site-specific Cancers. June 19, 2009

- Antioxidant Vitamins C and E and Reduction in the Risk of Site-Specific Cancers. June 19, 2009

- Tomatoes and Prostate, Ovarian, Gastric, and Pancreatic Cancers (American Longevity Petition). November 8, 2005

- Tomatoes and Prostate Cancer (Lycopene Heath Claim Coalition Petition). November 8, 2005

- Calcium and Colon/Rectal Cancer and Calcium and Colon/Rectal Polyps. October 12, 2005

- Selenium and Certain Cancers. April 28, 2003

- Antioxidant Vitamins and Risk of Certain Cancers. April 1, 2003

- Oleic Acid and Coronary Heart Disease (Corbion Biotech Petition). November 19, 2018

- Folic Acid, Vitamin B6, and Vitamin B12 and Vascular Disease. November 28, 2000

- Macadamia Nuts and Reduced Risk of Coronary Heart Disease. July 24, 2017

- Walnuts and Coronary Heart Disease. March 9, 2004 
- Nuts and Coronary Heart Disease. July 14, 2003

- Omega-3 Fatty Acids and Reduced Risk of Coronary Heart Disease. September 8, 2004

- Soybean Oil and Reduced Risk of Coronary Heart Disease. July 31, 2017

- Corn Oil and Corn Oil-Containing Products and a Reduced Risk of Heart Disease. March 26, 2007

- Unsaturated Fatty Acids from Canola Oil and Reduced Risk of Coronary Heart Disease. October 6, 2006

- Monounsaturated Fatty Acids from Olive Oil and Coronary Heart Disease. November 1, 2004

- Phosphatidylserine and Cognitive Dysfunction and Dementia. May 13, 2003

- High-Amylose Maize Starch and Reduced Risk Type 2 Diabetes Mellitus. December 12, 2016

- Psyllium Husk and a Reduced Risk of Type 2 Diabetes. External Link Disclaimer June 24, 2014

- Whole Grains and a Reduced Risk of Diabetes Mellitus Type 2. September 11, 2013

- Chromium Picolinate and a Reduced Risk of Insulin Resistance, Type 2 Diabetes. August 25, 2005

- Eicosapentaenoic Acid and Docosahexaenoic Acid and Reduction of Blood Pressure in the General Population. June 19, 2019

- Calcium and Hypertension, Pregnancy-Induced Hypertension, and Preeclampsia. October 12, 2005

- Folic Acid and Neural Tube Defects. April 3, 2007

- Ground Peanuts and Reduced Risk of Developing Peanut Allergy. September 7, 2017

Source: FDA (2017).

Nutrient Content Claim Categories (United States)

- Calories Claims

- Total Fat Claims

- Saturated Fat Claims

- Cholesterol Claims

- Sodium Claims

- Sugars Claims

Source: FDA 2013. 
Appendix 2. Descriptions and Sources of Price and Quantity Data

\begin{tabular}{|c|c|c|c|}
\hline $\begin{array}{l}\text { Demand } \\
\text { System }\end{array}$ & Commodity & $\begin{array}{l}\text { Quantity Data } \\
\text { Description }\end{array}$ & Price Data Description \\
\hline \multirow[t]{3}{*}{$\begin{array}{l}\text { Fats (United } \\
\text { States) }\end{array}$} & Butter & $\begin{array}{l}\text { Annual pounds of butter } \\
\text { available per capita } \\
\text { Source: ERS (2017d) }\end{array}$ & $\begin{array}{l}\text { Consumer price index for } \\
\text { poultry } \\
\text { Source: BLS (2017a) }\end{array}$ \\
\hline & Margarine & $\begin{array}{c}\text { Annual pounds of } \\
\text { margarine available per } \\
\text { capita } \\
\text { Source: ERS (2017b) }\end{array}$ & $\begin{array}{l}\text { Consumer price index for } \\
\text { fresh or frozen pork } \\
\text { Source: ERS (2017b) }\end{array}$ \\
\hline & Lard & $\begin{array}{l}\text { Annual pounds of lard } \\
\text { available per capita } \\
\text { Source: ERS (2017c) }\end{array}$ & $\begin{array}{c}\text { Consumer price index for } \\
\text { beef and veal } \\
\text { Source: ERS }(2017 \mathrm{c})\end{array}$ \\
\hline \multirow[t]{3}{*}{$\begin{array}{l}\text { Meats (United } \\
\text { States) }\end{array}$} & Poultry & $\begin{array}{c}\text { Annual pounds of } \\
\text { chicken, broilers and } \\
\text { turkey available per } \\
\text { capita on an eviscerated } \\
\text { weight basis } \\
\text { Source: } \text { ERS (2017a) }\end{array}$ & $\begin{array}{c}\text { Consumer price index for } \\
\text { poultry } \\
\text { Source: BLS (2017b) }\end{array}$ \\
\hline & Pork & $\begin{array}{l}\text { Annual pounds of pork } \\
\text { available per capita on a } \\
\text { retail weight basis } \\
\text { Source: } \text { ERS }(2017 \mathrm{a})\end{array}$ & $\begin{array}{l}\text { Consumer price index for } \\
\text { fresh or frozen pork } \\
\text { Source: BLS }(2017 \mathrm{c})\end{array}$ \\
\hline & Beef & $\begin{array}{l}\text { Annual pounds of beef } \\
\text { and veal available per } \\
\text { capita on a retail weight } \\
\text { basis } \\
\text { Source: } \text { ERS (2017a) }\end{array}$ & $\begin{array}{c}\text { Consumer price index for } \\
\text { beef and veal } \\
\text { Source: BLS (2017d) }\end{array}$ \\
\hline
\end{tabular}

Source: Authors. 
